\title{
THE VALUE OF ASSESSING MYOCARDIAL DEFORMATION AT RECOVERY AFTER DOBUTAMINE STRESS ECHOCARDIOGRAPHY
}

\author{
HuI-JEONG HWANG, MD, HyAE-MIN LEE, MD, IN-Ho YANG, MD, JUNG LOK LEE, MD, \\ HYUN YOUNG PAK, MD, CHANG-BUM PARK, MD, EUN-SUN JIN, MD, JIN-MAN CHO, MD, \\ CHONG-JIN KIM, MD, AND IL SUK SOHN, MD \\ DEPARTMENT OF CARDIOLOGY, KYUNG HEE UNIVERSITY HOSPITAL AT GANGDONG, KYUNG HEE UNIVERSITY COLLEGE OF MEDICINE, \\ SEOUL, KOREA
}

BACKGROUND: The purpose of this study was to evaluate whether performing an assessment of myocardial deformation using speckle tracking imaging during the recovery period after dobutamine stress echocardiography (DSE) allows detection of significant coronary artery disease (CAD) in patients with chest discomfort.

METHODS: DSE and coronary angiography were performed in 44 patients with chest discomfort. The mean global longitudinal peak systolic strain (GLS) was measured at rest, at low stress (dobutamine infusion rate of $10 \mu \mathrm{g} / \mathrm{kg} / \mathrm{min}$ ) and at recovery $(5 \mathrm{~min}$ after cessation of dobutamine infusion) of DSE using automated function imaging with apical views. Fractional flow reserve (FFR) was also performed in patients with intermediate coronary stenosis. CAD was defined as having a $\geq 70 \%$ diameter stenosis on coronary angiography or as having a FFR $<0.8$. Patients were divided two groups based on the absence or presence of CAD [CAD (-) group vs. CAD (+) group].

RESULTS: There were no significant differences in the clinical characteristics and results of conventional echocardiography between the two groups. GLS at recovery was lower in the CAD (+) group than in the CAD (-) group $(-18.0 \pm 3.4 \%$ vs. $-21.0 \pm$ $1.9 \%, p=0.003$ ). The optimal cutoff of GLS at recovery for detection of CAD was $-19 \%$ (sensitivity of $70.6 \%$, specificity of $83.3 \%)$.

CONCLUSION: Assessment of GLS at recovery of DSE is a reliable and objective method for detection of CAD. This finding may suggest that systolic myocardial stunning remains even after recovery of wall motion abnormalities in patients with CAD.

KEY WORDS: Dobutamine $\cdot$ Stress echocardiography $\cdot$ Myocardial stunning $\cdot$ Speckle tracking imaging.

\section{INTRODUCTION}

Dobutamine stress echocardiography (DSE) is a well-established method for detecting myocardial ischemia. The classic echocardiographic findings of ischemia are new or worsening abnormalities of radial wall thickening. ${ }^{1)}$ However, interpretation of these findings is subjective and dependent on experience. ${ }^{23)}$ Although speckle tracking strain imaging (STI) has been introduced as a novel method to overcome these limitations, ${ }^{14)}$ wider application of STI in clinical practice has been constrained by technical problems such as image quality, frame rate ${ }^{5)}$ and signal to noise ratio. ${ }^{6)}$ In fact, the technical problem may be particularly questioned at peak-dose dobutamine.

Myocardial stunning occurs after dobutamine or exercise induced ischemia. ${ }^{78)}$ Due to the ischemic cascade, persistent wall motion abnormalities (WMA) after ischemic insults are observed for a duration beyond the resolution of chest pain or electrocardiographic change. ${ }^{8)}$ However, little is known about whether persistence of induced ischemia during the recovery period after DSE helps in the detection of significant coronary artery disease (CAD). Thus, the goal of this study was to investigate whether assessment of myocardial deformation using

- Received: July 1, 2014 •Revised: August 21, 2014 •Accepted: August 22, 2014

- Address for Correspondence: II Suk Sohn, Department of Cardiology, Kyung Hee University Hospital at Gangdong, Kyung Hee University College of Medicine,

892 Dongnam-ro, Gangdong-gu, Seoul 134-727, Korea Tel: +82-2-440-6108, Fax: +82-2-440-7242, E-mail: issohn@khu.ac.kr

- This is an Open Access article distributed under the terms of the Creative Commons Attribution Non-Commercial License (http://creativecommons.org/licenses/by-nc/3.0)

which permits unrestricted non-commercial use, distribution, and reproduction in any medium, provided the original work is properly cited. 
STI during the recovery period after DSE allows for detection of CAD in patients with chest discomfort.

\section{METHODS}

\section{STUDY POPULATION}

Fifty-five consecutive patients with chest discomfort who underwent DSE and coronary angiography from October 2011 to December 2012 were recruited. Patients with acute coronary syndrome, WMA at rest or previous myocardial infarction, previous cardiac surgery, artificial pacemaker, non-sinus rhythm such as atrial fibrillation, valvular heart disease of greater than moderate grade, systolic dysfunction less than left ventricular (LV) ejection fraction $(\mathrm{EF})<40 \%$ and systemic diseases including chronic obstructive pulmonary disease, renal failure and hepatic failure were excluded from the study. Eleven patients were excluded from the analysis, including six patients with inadequate ultrasound images and five patients with WMA at rest. The remaining 44 patients [age, $65 \pm 9$ years; 23 men (52\%)] were ultimately enrolled in this study. All patients gave written informed consent before undergoing DSE. This study was approved by the hospital ethics committees (IRB 2011-069).

\section{DOBUTAMINE STRESS ECHOCARDIOGRAPHY}

\section{DOBUTAMINE STRESS AND IMAGE ACQUISITION}

All patients underwent DSE using a standard protocol ${ }^{9)}$ with an incremental dobutamine infusion rate of 5, 10, 20, 30 , and $40 \mu \mathrm{g} / \mathrm{kg} / \mathrm{min}$ every 3 minutes and up to $1 \mathrm{mg}$ of atropine if the target heart rate ( $85 \%$ of the age-predicted maximal heart rate) was not achieved. Heart rate, blood pressure, 12-lead electrocardiography and symptoms during DSE were recorded at each DSE stage. Beta-blockers and calcium channel blockers (non-dihydropyridines) were discontinued at least two days prior to the test. Criteria for terminating the test were completion of the protocol, development of new WMA, severe chest pain, systolic blood pressure (SBP) $>220 \mathrm{mmHg}$ or diastolic blood pressure (DBP) > $120 \mathrm{mmHg}$, symptomatic hypotension and serious ventricular or supraventricular arrhythmias. The examinations were performed in the left supine position with a Vivid E9 scanner (GE Vingmed Ultrasound, Horten, Norway). Complete 2-dimensional, color, pulsed, and continuous wave Doppler echocardiography were performed at rest according to standard techniques. ${ }^{10111}$ Two cine loops from the apical 4-, 3-, and 2-chamber views were acquired for assessment of myocardial deformation in the end-expiratory holding state at rest, after dobutamine infusion at a rate of $10 \mu \mathrm{g} / \mathrm{kg} / \mathrm{min}$ (low stress) and 5 min after cessation of dobutamine infusion (recovery), respectively. The 2-dimensional frame rates ranged between 50/s and 80/s. All images were digitally stored on hard discs for offline analysis (EchoPAC SW version 6.0.0, GE Vingmed Ultrasound AS).
ANALYSIS OF CONVENTIONAL ECHOCARDIOGRAPHY AND SPECKLE TRACKING IMAGING

Wall motion analyses ${ }^{12)}$ were assessed using a 17 myocardial segment model at each DSE stage by one experienced reader who was blinded to all patient data.

The mean global longitudinal peak systolic strain (GLS) was quantified at rest, low stress and recovery of DSE using automated function imaging, which is an imaging technique based on STI. ${ }^{13)}$ The values of GLS were assessed by an additional interpreter without information about clinical characteristics, DSE and coronary angiography (CAG) results. All data were exported to a spread-sheet (Microsoft excel 2002, Microsoft Corporation, Redmond, WA, USA).

\section{CORONARY ANGIOGRAPHY AND FRACTIONAL FLOW RESERVE}

CAG was performed in all patients within $9.7 \pm 23.9$ days from DSE according to standard techniques. Angiographic results were analyzed by an experienced observer. Fractional flow reserve (FFR) with an intracoronary pressure guide wire (Certus Wire, Radi Medical Systems, Uppsala, Sweden) was also performed in the intermediate coronary artery lesion $(30-70 \%$ diameter stenosis). ${ }^{14)}$ At this time, intravenous adenosine infusion $(140 \mu \mathrm{g} / \mathrm{kg} / \mathrm{min})$ was used to achieve a maximal steady state of hyperemia. ${ }^{15)}$ Significant coronary stenosis was defined as having $\mathrm{a} \geq 70 \%$ diameter stenosis as determined by computer-assisted quantitative CAG using multiple planes (QCA Quantcor, Siemens, Forchheim, Germany) or FFR $<0.8 .{ }^{16)}$ Patients with these findings were assigned to the $\mathrm{CAD}(+)$ group.

\section{STATISTICAL ANALYSIS}

Statistical analyses were performed using SPSS for Windows, version 15.0 (SPSS Inc., Chicago, IL, USA). Continuous variables were expressed as the mean \pm standard deviations and were compared using an independent Student $t$ test. Categorical variables were expressed as group percentages and were compared using the $\chi^{2}$ test. The intra-observer variability for values of GLS on Bland-Altman analysis was tested in 10 patients and the coefficient of variability was $4.8 \%$ at rest, $5.8 \%$ at low stress and $5.9 \%$ at recovery. ${ }^{17)}$ Regression analysis was performed to assess whether values of GLS is independently associated with presence of CAD. The optimal GLS cutoff values for detecting CAD at each DSE stage were determined from receiver operating characteristic (ROC) curves. The area under the ROC curve (AUC) was used to compare the diagnostic validity, and a z-score was calculated to determine the difference of AUCs. ${ }^{18)}$ Statistical significance was considered to be a $p$ value of less than 0.05 .

\section{RESULTS}

\section{PATIENT CHARACTERISTICS}

Fifteen patients with a finding of greater than $70 \%$ diame- 
ter stenosis on CAG were included in the CAD (+) group. Three patients with intermediate CAD were also included in the CAD (+) group after FFR analysis. The remaining 26 patients were classified into the CAD (-) group. The baseline clinical characteristics and lesions of significant stenosis are summarized in Table 1. Clinical characteristics including age, sex, risk factors, SBP, and DBP were not different between the two groups.

In the CAD (+) group, a significant stenosis was present in the left main artery in five patients $(28 \%)$, in the left anterior descending artery in 12 patients (67\%), in the left circumflex artery in eight patients (44\%) and in the right coronary artery in four patients $(22 \%)$. Eleven patients $(61 \%)$ had single vessel disease, five (28\%) had two vessel disease and two (11\%) had three vessel disease.
The conventional echocardiographic findings are summarized in Table 2. LV thickness, LV size, left atrial size, LVEF, and several diastolic indices were not different between the two groups.

\section{HEMODYNAMICS AND WALL MOTION ANALYSIS}

Target heart rate during DSE was achieved in 37 patients $(84 \%)$. In the remaining seven patients, DSE was terminated due to ischemic signs in five patients, symptomatic hypotension in one patient and an inability to achieve the target heart rate despite dobutamine and atropine administration in one patient.

Neither group differed significantly with respect to SBP and DBP at any DSE stage (Fig. 1). At rest, patients with CAD significantly had higher heart rates than patients without CAD

Table 1. Baseline clinical characteristics and lesions of significant coronary stenosis

\begin{tabular}{|c|c|c|c|}
\hline Variables & $\mathrm{CAD}(-), \mathrm{n}=26$ & $\mathrm{CAD}(+), \mathrm{n}=18$ & $p$ value \\
\hline Age (yr) & $66 \pm 8$ & $64 \pm 11$ & 0.393 \\
\hline Male, $\mathrm{n}(\%)$ & $13(50)$ & $10(56)$ & 0.717 \\
\hline Body mass index, $\mathrm{kg} / \mathrm{m}^{2}$ & $23.6 \pm 2.1$ & $23.8 \pm 2.9$ & 0.786 \\
\hline Smoking, n (\%) & $11(45.8)$ & $9(50)$ & 0.654 \\
\hline Hypertension, n (\%) & $17(65)$ & $13(72)$ & 0.632 \\
\hline Diabetes, n (\%) & $7(27)$ & $8(44)$ & 0.228 \\
\hline Stroke, n (\%) & $1(4)$ & $1(6)$ & 1.000 \\
\hline Dyslipidemia, n (\%) & $14(54)$ & $11(61)$ & 0.480 \\
\hline Baseline SBP, mmHg & $132 \pm 20$ & $132 \pm 21$ & 0.947 \\
\hline Baseline DBP, mmHg & $72 \pm 11$ & $77 \pm 13$ & 0.150 \\
\hline Baseline HR, bpm & $62 \pm 9$ & $70 \pm 12$ & 0.010 \\
\hline \multicolumn{4}{|c|}{ Lesions of significant stenosis } \\
\hline $\mathrm{LM}, \mathrm{n}(\%)$ & & $5(28)$ & \\
\hline $\mathrm{LAD}, \mathrm{n}(\%)$ & & $12(67)$ & \\
\hline $\mathrm{LCx}, \mathrm{n}(\%)$ & & $8(44)$ & \\
\hline $\mathrm{RCA}, \mathrm{n}(\%)$ & & $4(22)$ & \\
\hline
\end{tabular}

Data is expressed as mean \pm standard deviation. CAD: coronary artery disease, SBP: systolic blood pressure, DBP: diastolic blood pressure, HR: heart rate, LM: left main artery, LAD: left anterior descending artery, LCx: left circumflex artery, RCA: right coronary artery

Table 2. Baseline conventional echocardiography

\begin{tabular}{|c|c|c|c|}
\hline Variables & $\mathrm{CAD}(-), \mathrm{n}=26$ & $\operatorname{CAD}(+), \mathrm{n}=18$ & $p$ value \\
\hline IVSth, mm & $8.9 \pm 1.9$ & $8.8 \pm 1.8$ & 0.929 \\
\hline LVPWth, mm & $8.9 \pm 1.4$ & $9.4 \pm 1.3$ & 0.243 \\
\hline LVDd, mm & $45.7 \pm 4.3$ & $45.7 \pm 5.3$ & 0.993 \\
\hline LVDs, mm & $29.6 \pm 4.5$ & $29.7 \pm 4.4$ & 0.916 \\
\hline $\mathrm{LAD}, \mathrm{mm}$ & $36.5 \pm 3.9$ & $36.6 \pm 4.1$ & 0.953 \\
\hline LAVI, $\mathrm{mL} / \mathrm{m}^{2}$ & $29.2 \pm 7.0$ & $26.5 \pm 4.9$ & 0.174 \\
\hline Ejection fraction, $\%$ & $66.7 \pm 5.3$ & $67.3 \pm 7.3$ & 0.752 \\
\hline $\mathrm{E} / \mathrm{A}$ ratio & $0.9 \pm 0.3$ & $0.8 \pm 0.2$ & 0.883 \\
\hline$E / e^{\prime}$ & $12.3 \pm 3.8$ & $12.1 \pm 4.6$ & 0.837 \\
\hline IVRT, ms & $88.8 \pm 18.9$ & $85.0 \pm 14.4$ & 0.482 \\
\hline
\end{tabular}

Data is expressed as mean \pm standard deviation. CAD: coronary artery disease, IVSth: interventricular septal thickness, LVPWth: end-diastolic left ventricular posterior wall thickness, LVDd: diastolic left ventricular dimension, LVDs: systolic left ventricular dimension, LAD: left atrial dimension, LAVI: left atrial volume index, E: early diastolic transmitral velocity, A: late diastolic transmitral velocity, e': early diastolic mitral annular velocity, IVRT: isovolumic relaxation time 


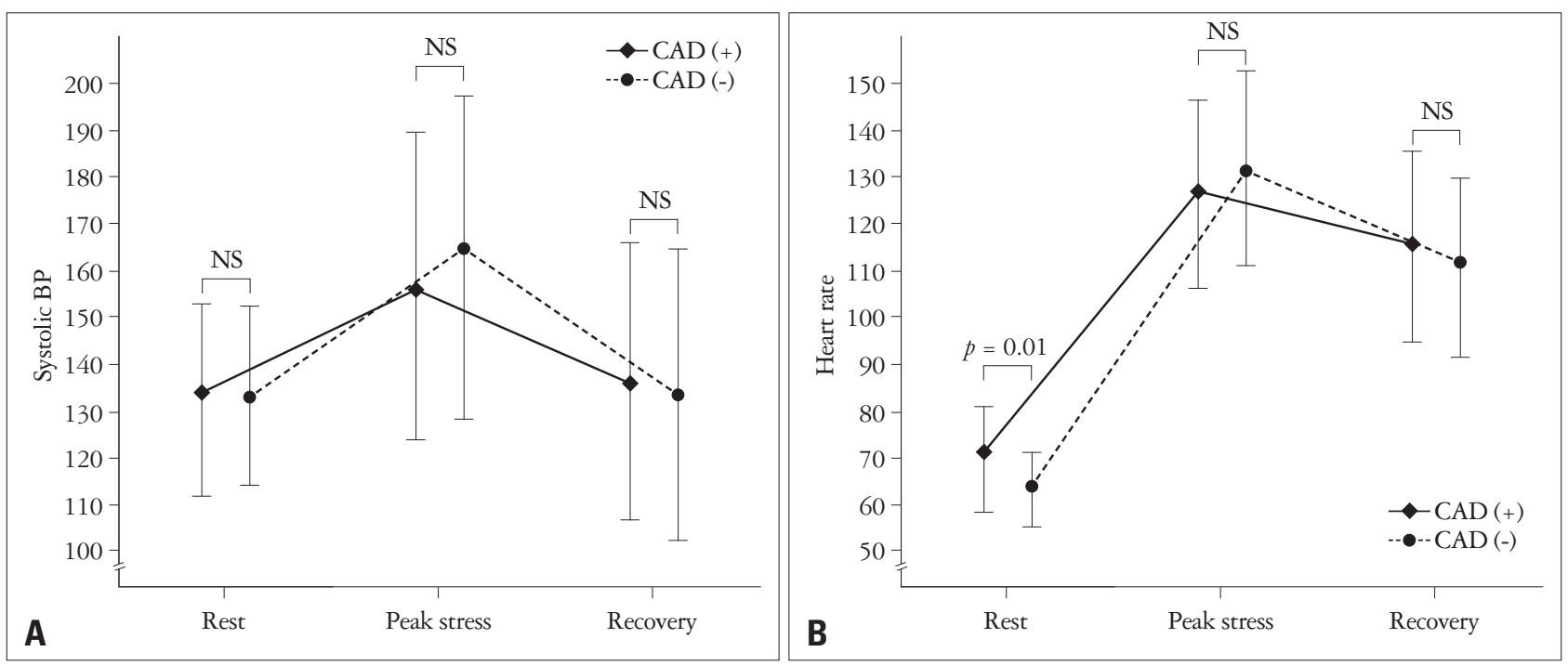

Fig. 1. Changes in hemodynamics at each dobutamine stress stage: systolic blood pressure (BP) (A), heart rate (B). The group with significant coronary artery disease $(C A D)$ has higher heart rates at rest than the group without CAD. NS: non-significant $p$ value.
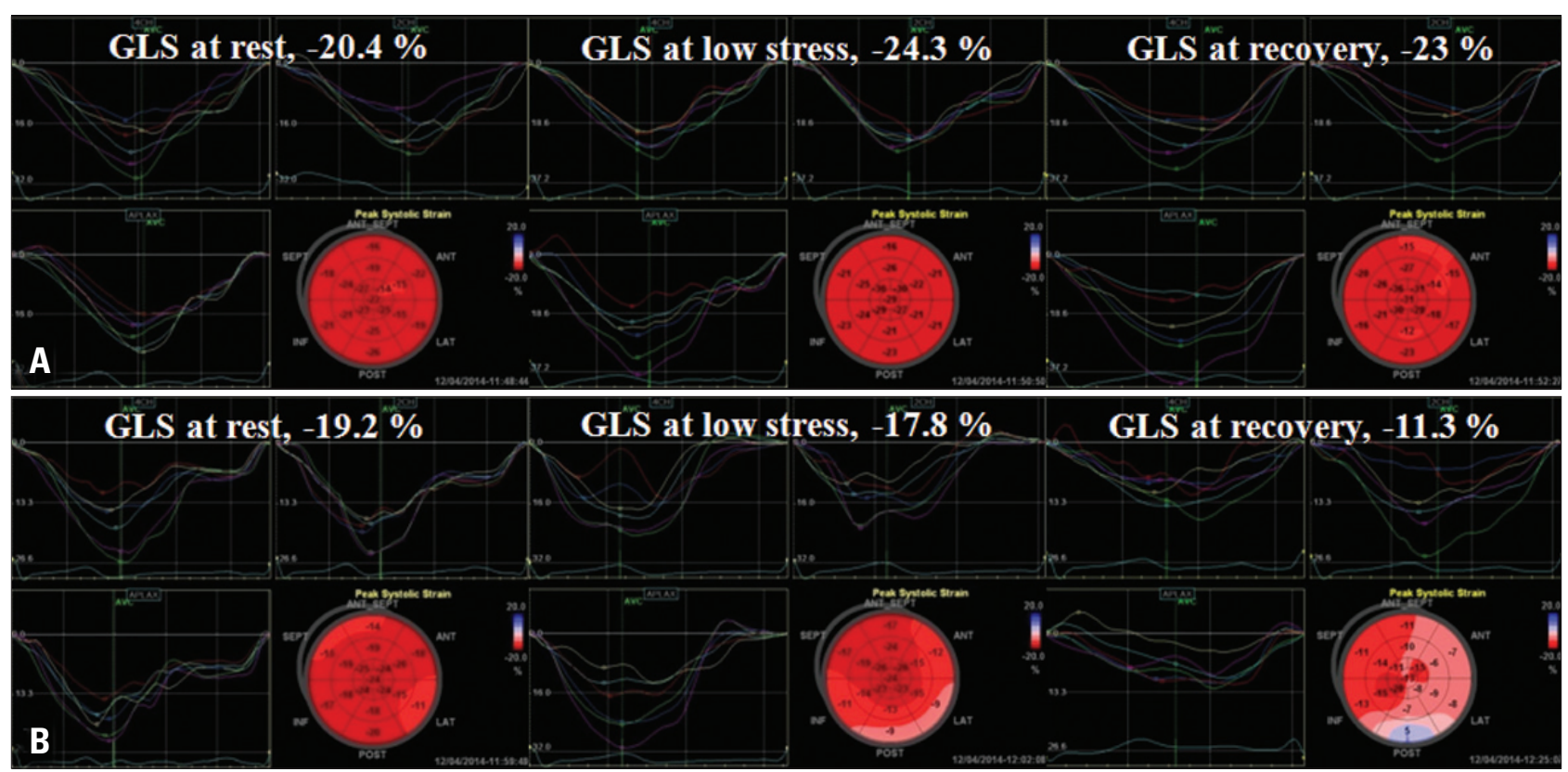

Fig. 2. Representative cases with longitudinal strain curves and bull's eye plots showing segmental longitudinal peak systolic strain. A: A 75-year-old female without coronary artery stenosis. The bull's eye plot shows high and homogeneous peak systolic longitudinal strain for the entire left ventricle at each dobutamine stress stage and more increased contractility at low stress and at recovery compared with rest. B: A 55-year-old male with significant stenosis in the left main and proximal left circumflex arteries. The bull's eye plot shows decreased peak systolic longitudinal strain in the inferolateral and anterolateral segments at low stress, which extends into the anterior segments at recovery. These findings are consistent with the region of significant coronary stenosis on coronary angiography. Additionally, decreased values of mean global longitudinal peak systolic strain are observed at low stress and at recovery compared with rest. GLS: global longitudinal peak systolic strain.

(Table 1, Fig. 1). However, there were no significant differences in heart rates at peak stress and recovery between the two groups (Fig. 1).

Visual wall motion assessment was successfully performed on all patients at each DSE stage. WMA were observed in four patients $(15.4 \%)$ in the CAD (-) group and in 13 patients $(72 \%)$ in the CAD (+) group. The sensitivity and specificity of WMA for CAD were $72.2 \%$ and $70.6 \%$, respectively (Ta- ble 3). WMA were normalized at recovery of DSE except in one patient with two vessel disease.

\section{QUANTITATIVE GLOBAL LONGITUDINAL PEAK SYSTOLIC STRAIN AND ACCURACY}

Data are exemplified in Fig. 2 and summarized in Fig. 3. In patients without CAD, the values of GLS significantly increased at low stress compared with those at rest $(p<0.001)$, and then 
decreased at recovery $(p<0.001$ in comparison with low stress, $p=0.107$ in comparison with rest). On the other hand, the values of GLS in patients with CAD slightly increased at low stress $(p=0.055$ in comparison with rest) and then significantly decreased at recovery $(p=0.002$ in comparison with low stress, $p$ $=0.046$ in comparison with rest). Both groups were not significantly different in the values of GLS at rest and at low stress. On the other hand, patients with CAD significantly had lower value of GLS at recovery than patients without CAD (Fig. 3).

Upon ROC analysis (Fig. 4), the values of GLS at recovery significantly had greater AUCs than the values of GLS at rest ( $\mathrm{z}$ statistic $=2.20, p=0.028)$. However, these values were not greater than the values of GLS at low stress (z statistic $=1.12$, $p=0.264)$. The optimal cutoff value of GLS at recovery for prediction of CAD was $-19 \%$, which resulted in a sensitivity and specificity of $70.6 \%$ and $83.3 \%$, respectively. The sensitivity, specificity and positive and negative predictive values between visual WMA at peak stress and the quantitative GLS technique at recovery were similar (Table 3). Low value of GLS at recovery was associated with presence of CAD after adjusted with age, sex, hypertension, and diabetes (data not shown).

\section{DISCUSSION}

Because conventional interpretation of DSE is often subjective and highly dependent on experience, ${ }^{233}$ quantification of LV function by STI is utilized to obtain an objective assessment. However, it has not been used commercially for several reasons such as the difficulty in achieving quality image acquisition with a high frame rate and in maintaining respiratory holding during imaging saving, and the fact the post-processing steps required for analysis are time consuming. ${ }^{1556)}$ Assessment of STI at peak stress of DSE is especially difficult because of an inadequate low frame rate for the rapid heart rate, failure to maintain respiratory holding in symptomatic patients, subsequent tracking problems and the development of signal to noise due to hyperdynamic LV contractility and excessive annular motion. ${ }^{1920)}$ On the other hand, assessment of STI at recovery is easier because of the ease of respiratory control due to improvement in symptoms, lower heart rate and decreased myocardial hyper-contractility. Owing to the development of tool that allow for better measurement, several recent works ${ }^{821)}$ have shown that transient ischemic injury after DSE persists much longer than previously thought. Tsoukas et al. ${ }^{8)}$ showed that delayed recovery of WMA after DSE occurs after the resolution of symptoms and electrocardiographic changes and can persist for at least 5 minutes in $90 \%$ of patients. Ishii et al. ${ }^{21)}$ demonstrated that post-ischemic diastolic stunning after complete systolic functional recovery can persist for more than 24 hour after reperfusion. Likewise, we showed that the values of GLS at recovery after DSE may be a good marker for the detection of CAD, as well as newly developed WMA at peak stress. Furthermore, comparison of their respective diagnostic accuracies showed that the values of GLS

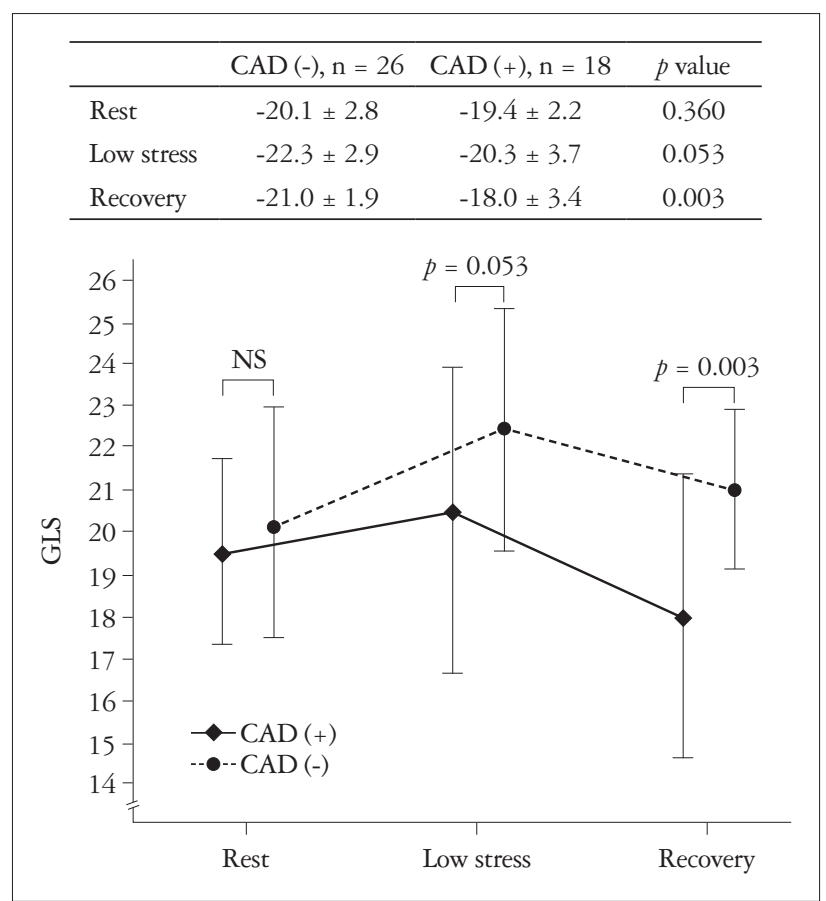

Fig. 3. Changes in values of global longitudinal peak systolic strain (GLS) during dobutamine stress echocardiography. Lower values of GLS are observed in the CAD (+) group compared with the CAD (-) group at low stress and at recovery. CAD: coronary artery disease, NS: non-significant $p$ value.

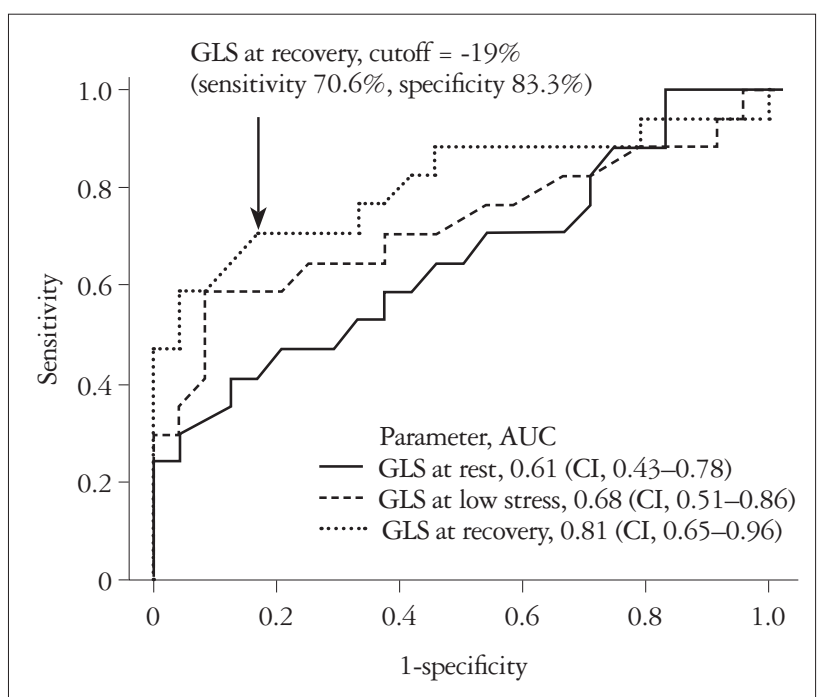

Fig. 4. Receiver-operating characteristic curves of global longitudinal peak systolic strain (GLS) at each dobutamine stress stage for the prediction of coronary artery disease (CAD). A sensitivity of $70.6 \%$ and a specificity of $83.3 \%$ are observed when the cutoff value of GLS at recovery is less than $-19 \%$ for the prediction of CAD. AUC: area under the receiver operating characteristic curve, $\mathrm{Cl}$ : confidence interval of AUC.

at recovery were comparable with the expert wall motion analysis at peak stress (Table 3). On the other hand, WMA was normalized within 5 min after DSE in all patients with one exception. In this patient, WMA persisted for $15 \mathrm{~min}$.

The amplitude cutoffs of GLS for the prediction of CAD at 


\begin{tabular}{|c|c|c|c|}
\hline & WMA $(+)$ at peak stress & GLS at recovery $<-19 \%$ & $p$ value \\
\hline Sensitivity & $72 \%$ & $71 \%$ & 1.000 \\
\hline Specificity & $85 \%$ & $83 \%$ & 1.000 \\
\hline Accuracy & $77 \%$ & $78 \%$ & 1.000 \\
\hline
\end{tabular}

GLS: mean global longitudinal peak systolic strain, CAD: coronary artery disease, WMA (+): existence of wall motion abnormality

rest and at low stress are rather low (Fig. 4). This may be due to individual differences in the contractile state at rest and in the chronotropic response to dobutamine at low stress. In fact, comorbidities such as male, hypertension and diabetes are associated with low global strain regardless of myocardial ischemia. ${ }^{22-24)}$ Additionally, low dose dobutamine infusion is associated with insufficient sensitivity. ${ }^{1)}$

In this study, the sensitivity of newly developed WMA at peak stress for detection of CAD was slightly lower than in earlier studies, ${ }^{23325)}$ in which an average sensitivity of $>80 \%$ was reported. However, using a similar patient cohort as utilized in our study, Ingul et al. ${ }^{26)}$ showed a similar sensitivity of developed WMA at peak stress. In fact, the accuracy of developed WMA at peak stress is known to be greater in patients with ischemia in the left anterior descending artery than in patients with ischemia in the left circumflex artery or right coronary artery, and also in the multi-vessel disease cases than in the single vessel disease cases. ${ }^{1)}$

This study has some limitations. First, we did not analyze strain rate. In fact, the noise in the strain rate signal increased with higher heart rates and the image quality decreased. ${ }^{27)}$ Second, we only showed global longitudinal strain analysis using an automatic functional imaging method. Although automatic functional imaging based on the speckle tracking method is less time consuming and feasible, objective assessment of regional myocardial function is still incomplete. ${ }^{26)}$ And, in earlier studies, ${ }^{1928) 29)}$ longitudinal strain had a higher diagnostic accuracy for detection of CAD than circumferential or radial strain. This is likely due to the fact that longitudinal strain is primarily determined by subendocardial fibers vulnerable to ischemia and from the LV base to apex and has higher reproducibility and correlation with sonomicrometry. ${ }^{21)}$ Third, the combination of expert wall motion analysis and the values of GLS did not have higher diagnostic accuracy than either the wall motion analysis or the values of GLS individually (data not shown). Therefore, the values of GLS at recovery may be more useful to an inexperienced interpreter of wall motion analysis than to an expert. The fourth limitation is that this was a study of relatively small sample size. Therefore, we could not estimate that the value of GLS at recovery has a different accuracy according to CAD lesions in the prediction of CAD.

In conclusion, assessment of GLS at recovery of DSE might be a reliable and objective method for detection of significant CAD. This finding may suggest that systolic stunning after a transient ischemic event persists and that assessment by GLS during the recovery period allows this phenomenon to be objectively and quantitatively assessed.

\section{- Acknowledgements}

This study was supported by a grant from the Korean Society of Echocardiography (Industrial-educational cooperation 2012).

\section{REFERENCES}

1. Szymanski C, Pierard L, Lancellotti P. Imaging techniques in coronary atherosclerotic disease: dobutamine stress echocardiography-evidence and perspectives. J Cardiovasc Med (Hagerstown) 2011;12:543-53.

2. Hoffmann R, Lethen H, Marwick T, Arnese M, Fioretti P, Pingitore A, Picano E, Buck T, Erbel R, Flachskampf FA, Hanrath P. Analysis of interinstitutional observer agreement in interpretation of dobutamine stress echocardiograms. J Am Coll Cardiol 1996;27:330-6.

3. Picano E, Lattanzi F, Orlandini A, Marini C, L'Abbate A. Stress echocardiography and the human factor: the importance of being expert. J Am Coll Cardiol 1991;17:666-9.

4. Anwar AM. Accuracy of two-dimensional speckle tracking echocardiography for the detection of significant coronary stenosis. J Cardiovasc Ultrasound 2013;21:177-82.

5. Bansal M, Jeffriess L, Leano R, Mundy J, Marwick TH. Assessment of myocardial viability at dobutamine echocardiography by deformation analysis using tissue velocity and speckle-tracking. JACC Cardiovasc Imaging 2010;3:121-31.

6. Voigt JU, Exner B, Schmiedehausen K, Huchzermeyer C, Reulbach U, Nixdorff U, Platsch G, Kuwert T, Daniel WG, Flachskampf FA. Strain-rate imaging during dobutamine stress echocardiography provides objective evidence of inducible ischemia. Circulation 2003;107:2120-6.

7. Kloner RA, Bolli R, Marban E, Reinlib L, Braunwald E. Medical and cellular implications of stunning, bibernation, and preconditioning: an NHLBI workshop. Circulation 1998;97:1848-67.

8. Tsoukas A, Ikonomidis I, Cokkinos P, Nihoyannopoulos P. Significance of persistent left ventricular dysfunction during recovery after dobutamine stress echocardiography. J Am Coll Cardiol 1997;30:621-6.

9. Pellikka PA, Nagueh SF, Elhendy AA, Kuehl CA, Sawada SG; American Society of Echocardiography. American Society of Echocardiography recommendations for performance, interpretation, and application of stress echocardiography. J Am Soc Echocardiogr 2007;20:1021-41.

10. Nishimura RA, Miller FA Jr, Callahan MJ, Benassi RC, Seward JB, Tajik AJ. Doppler echocardiography: theory, instrumentation, technique, and application. Mayo Clin Proc 1985;60:321-43.

11. Tajik AJ, Seward JB, Hagler DJ, Mair DD, Lie JT. Two-dimensional real-time ultrasonic imaging of the heart and great vessels. Technique, image orientation, structure identification, and validation. Mayo Clin Proc 1978;53:271-303.

12. Lang RM, Bierig M, Devereux RB, Flachskampf FA, Foster E, Pellikka PA, Picard MH, Roman MJ, Seward J, Shanewise JS, Solomon SD, Spencer KT, Sutton MS, Stewart WJ; Chamber Quantification Writing Group; American Society of Echocardiography's 
Guidelines and Standards Committee; European Association of Echocardiography. Recommendations for chamber quantification: a report from the American Society of Echocardiography's Guidelines and Standards Committee and the Chamber Quantification Writing Group, developed in conjunction with the European Association of Echocardiography, a branch of the European Society of Cardiology. J Am Soc Echocardiogr 2005;18: 1440-63.

13. Delgado V, Mollema SA, Ypenburg C, Tops LF, van der Wall EE, Schalij MJ, Bax JJ. Relation between global left ventricular longitudinal strain assessed with novel automated function imaging and biplane left ventricular ejection fraction in patients with coronary artery disease. J Am Soc Echocardiogr 2008;21:1244-50.

14. De Bruyne B, Sarma J. Fractional flow reserve: a review: invasive imaging. Heart 2008;94:949-59.

15. De Bruyne B, Pijls NH, Barbato E, Bartunek J, Bech JW, Wijns W, Heyndrickx GR. Intracoronary and intravenous adenosine 5'-triphosphate, adenosine, papaverine, and contrast medium to assess fractional flow reserve in humans. Circulation 2003;107:1877-83.

16. Pijls NH, De Bruyne B, Peels K, Van Der Voort PH, Bonnier HJ, Bartunek J Koolen JJ, Koolen JJ. Measurement of fractional flow reserve to assess the functional severity of coronary-artery stenoses. N Engl J Med 1996;334:1703-8.

17. Bland JM, Altman DG. Statistical methods for assessing agreement between two methods of clinical measurement. Lancet 1986;1:307-10.

18. DeLong ER, DeLong DM, Clarke-Pearson DL. Comparing the areas under two or more correlated receiver operating characteristic curves: a nonparametric approach. Biometrics 1988;44:837-45.

19. Ng AC, Sitges M, Pham PN, Tran da T, Delgado V, Bertini M, Nucifora G, Vidaic J, Allman C, Holman ER, Bax JJ, Leung DY. Incremental value of 2-dimensional speckle tracking strain imaging to wall motion analysis for detection of coronary artery disease in patients undergoing dobutamine stress echocardiography. Am Heart J 2009;158:836-44.

20. Hanekom L, Cho GY, Leano R, Jeffriess L, Marwick TH. Comparison of two-dimensional speckle and tissue Doppler strain measurement during dobutamine stress echocardiography: an angiographic correlation. Eur Heart J 2007;28:1765-72.

21. Ishii K, Suyama T, Imai M, Maenaka M, Yamanaka A, Makino Y,
Seino Y, Shimada K, Yoshikawa J. Abnormal regional left ventricular systolic and diastolic function in patients with coronary artery disease undergoing percutaneous coronary intervention: clinical significance of post-ischemic diastolic stunning. J Am Coll Cardiol 2009;54:1589-97.

22. Kocabay G, Muraru D, Peluso D, Cucchini U, Mihaila S, Padayattil-Jose S, Gentian D, Iliceto S, Vinereanu D, Badano LP. Normal Left Ventricular Mechanics by Two-dimensional Speckle-tracking Echocardiography. Reference Values in Healthy Adults. Rev Esp Cardiol (Engl Ed) 2014;67:651-8.

23. Dalen H, Thorstensen A, Romundstad PR, Aase SA, Stoylen A, Vatten LJ. Cardiovascular risk factors and systolic and diastolic cardiac function: a tissue Doppler and speckle tracking echocardiographic study. J Am Soc Echocardiogr 2011;24:322-32.e6.

24. Vinereanu D, Nicolaides E, Tweddel AC, Mädler CF, Holst B, Boden LE, Cinteza M, Rees AE, Fraser AG. Subclinical left ventricular dysfunction in asymptomatic patients with Type II diabetes mellitus, related to serum lipids and glycated haemoglobin. Clin Sci (Lond) 2003;105:591-9.

25. Sicari R, Nihoyannopoulos P, Evangelista A, Kasprzak J, Lancellotti P, Poldermans D, Voigt JU, Zamorano JL; European Association of Echocardiography. Stress echocardiography expert consensus statement: European Association of Echocardiography (EAE) (a registered branch of the ESC). Eur J Echocardiogr 2008;9:415-37.

26. Ingul CB, Stoylen A, Slordahl SA, Wiseth R, Burgess M, Marwick TH. Automated analysis of myocardial deformation at dobutamine stress echocardiography: an angiographic validation. J Am Coll Cardiol 2007; 49:1651-9.

27. Hoffmann R, Altiok E, Nowak B, Heussen N, Kühl H, Kaiser HJ, Büll U, Hanrath P. Strain rate measurement by doppler echocardiography allows improved assessment of myocardial viability inpatients with depressed left ventricular function. J Am Coll Cardiol 2002;39:443-9.

28. Gallagher KP, Osakada G, Matsuzaki M, Miller M, Kemper WS, Ross J Jr. Nonuniformity of inner and outer systolic wall thickening in conscious dogs. Am J Physiol 1985;249(2 Pt 2):H241-8.

29. Zhang Q, Fung JW, Yip GW, Chan JY, Lee AP, Lam YY, Wu LW, Wu EB, Yu CM. Improvement of left ventricular myocardial short-axis, but not long-axis function or torsion after cardiac resynchronisation therapy: an assessment by two-dimensional speckle tracking. Heart 2008;94:1464-71. 